\title{
A Case of Recalcitrant Psoriatic Arthritis to TNF Inhibitors Improved After Administration of Secukinumab, an IL-17A Inhibitor
}

\author{
Eleftherios Pelechas · Tereza Memi · Paraskevi V. Voulgari - Alexandros A. Drosos
}

Received: August 31, 2017 / Published online: October 11, 2017

(C) The Author(s) 2017. This article is an open access publication

\section{ABSTRACT}

Psoriatic arthritis (PsA) is a unique inflammatory arthritis due to the fact that patients have to deal not only with pain but also with their skin appearance, which may have a detrimental effect on their everyday lives and psychology. Treating a patient with PsA, improving both the musculoskeletal and skin symptoms is a challenge for the clinical rheumatologist. In this case, we present a patient of recalcitrant PsA to tumor necrosis factor inhibitors (TNFi) who had an exceptional improvement after administration of the interleukin-17A inhibitor (IL-17Ai) secukinumab.

Keywords: IL-17A inhibitor; Psoriatic arthritis; Secukinumab; TNF inhibitors

Enhanced content To view enhanced content for this article go to www.medengine.com/Redeem/ A5BCF0603E808A4C.

E. Pelechas · T. Memi · P. V. Voulgari .

A. A. Drosos $(\square)$

Rheumatology Clinic, Department of Internal

Medicine, Medical School, University of Ioannina,

Ioannina, Greece

e-mail: adrosos@cc.uoi.gr

\section{INTRODUCTION}

In the pre-TNF inhibitors (TNFi) era, there were enough cases of recalcitrant, moderate-to-severe, psoriatic arthritis (PsA) [1, 2]. Glucocorticoids (GCs), synthetic disease-modifying antirheumatic drugs (sDMARDs), retinoids, and photochemotherapy were the mainstay treatment for those cases, often with poor physician expectations because of significant side effects [3]. Since the approval of TNFi treatment for PSA, recalcitrant cases showed a dramatic decrease $[4,5]$. The introduction of the TNFi in the early 2000s, the first biologic disease-modifying antirheumatic drugs (bDMARDs) used in the treatment of PsA, showed a significant capacity to achieve states of low disease activity or remission and became the gold standard treatment with a promising efficacy/safety profile $[6,7]$. The first TNFi for moderate-to-severe PsA was etanercept [8]. Nowadays, the clinician has an extended armamentarium to combat PsA with new biologic agents already available (Table 1) or still under research.

We present a case of recalcitrant PsA to two TNFi, which showed a remarkable improvement after administration of secukinumab, an IL-17A inhibitor.

Informed consent, for the publication for this case report and any additional related information was taken from the patient involved in the study. 
Table 1 Biologic agents for PsA

\begin{tabular}{lll}
\hline Treatment & Target & Year of approval \\
\hline Etanercept & TNFi & 2002 \\
Adalimumab & TNFi & 2005 \\
Infliximab & TNFi & 2005 \\
Golimumab & TNFi & 2009 \\
Certolizumab & TNFi & 2013 \\
$\quad$ Pegol & & \\
Ustekinumab & IL12/IL23 & 2013 \\
Apremilast & PDE4 & 2014 \\
Secukinumab & IL17A & 2016 \\
Inflectra & TNFi-Biosimilar & 2015 \\
\hline
\end{tabular}

\section{CASE REPORT}

A 37-year-old female presented to our outpatient rheumatology clinic because of severe plaque psoriasis and arthritis involving the large joints, mainly knees, left ankle, and left elbow. She had been diagnosed with psoriasis since the age of 13 , and she had been treated with topical therapy with some improvement. She had no arthritis at that time and she developed asymmetrical polyarthritis 2 months prior to her visit to our department. Past medical and family history were unremarkable, and after an appropriate screen test, she was treated with methotrexate (MTX/15 mg/week) and small doses of prednisone (7.5 mg/day). After 2 months, she showed some clinical improvement, but her liver enzymes were elevated (AST $127 \mathrm{IU} / \mathrm{L}$, ALT $120 \mathrm{IU} / \mathrm{L})$, thus MTX was discontinued and cyclosporine-A (CSA/ $200 \mathrm{mg} /$ day) was added. After 3 months of CSA therapy she showed clinical improvement of skin manifestations but synovitis of both knees was evident with high acute phase reactants. Adalimumab was added ( $40 \mathrm{mg} / 14$ days) subcutaneously with significant clinical and laboratory improvement. However, after 8 months of adalimumab and CSA treatment, she had a disease flare-up with symmetrical synovitis, including both knees and ankles, as well as severe skin manifestations. Both drugs were discontinued and etanercept (50 mg/week) subcutaneously and leflunomide (20 mg/day) were started. Three months later, she had a significant clinical and laboratory response but she developed elevated liver enzymes once again. A workup for liver disease (ultrasonography, screening for hepatitis B and C) was negative. Leflunomide was discontinued and she carried on with etanercept $(50 \mathrm{mg} /$ week). She did quite well, but after 7 months of etanercept treatment she developed severe exacerbation of both skin and musculoskeletal involvement with disease activity score (DAS 28) 5.2 and a Psoriasis Area Severity Index (PASI) score 10.8 (Fig. 1a). After discussion with the patient, there was a switch from TNFi to secukinumab, an IL-17a inhibitor. She started on $300 \mathrm{mg}$ s.c. on weeks $0,1,2$, and 4 and monthly thereafter. On week 4, the patient came for follow-up and re-evaluation (Fig. 1b). She reported that except for the rapid skin improvement, there was a significant musculoskeletal improvement that she had never experienced in the past while using different sDMARDs or TNFi. PASI score was 2 and DAS 28 was 2.3. Secukinumab showed a dramatic and rapid response in the reduction of pain, followed by improvement of laboratory and clinical signs of joint inflammation. Skin disease also responded well after a short period of time which had a positive impact on patients' psychology. After 36 weeks of treatment with secukinumab, she is now free of joint pain and her skin has a near-normal appearance (Fig. 1c).

\section{DISCUSSION}

Treating a patient with PsA and improving both the musculoskeletal and skin symptoms is a challenge for the clinical rheumatologist. PsA is a unique inflammatory arthritis due to the fact that these patients have to deal not only with pain but also with their skin appearance, which may have a detrimental effect on their everyday live and psychology [9]. Many authors correlate PsA with anxiety and depression $[9,10]$, which may lead to flare-ups of the disease, and in fact there is a vicious circle between disease activity and psychological status of the patient. 

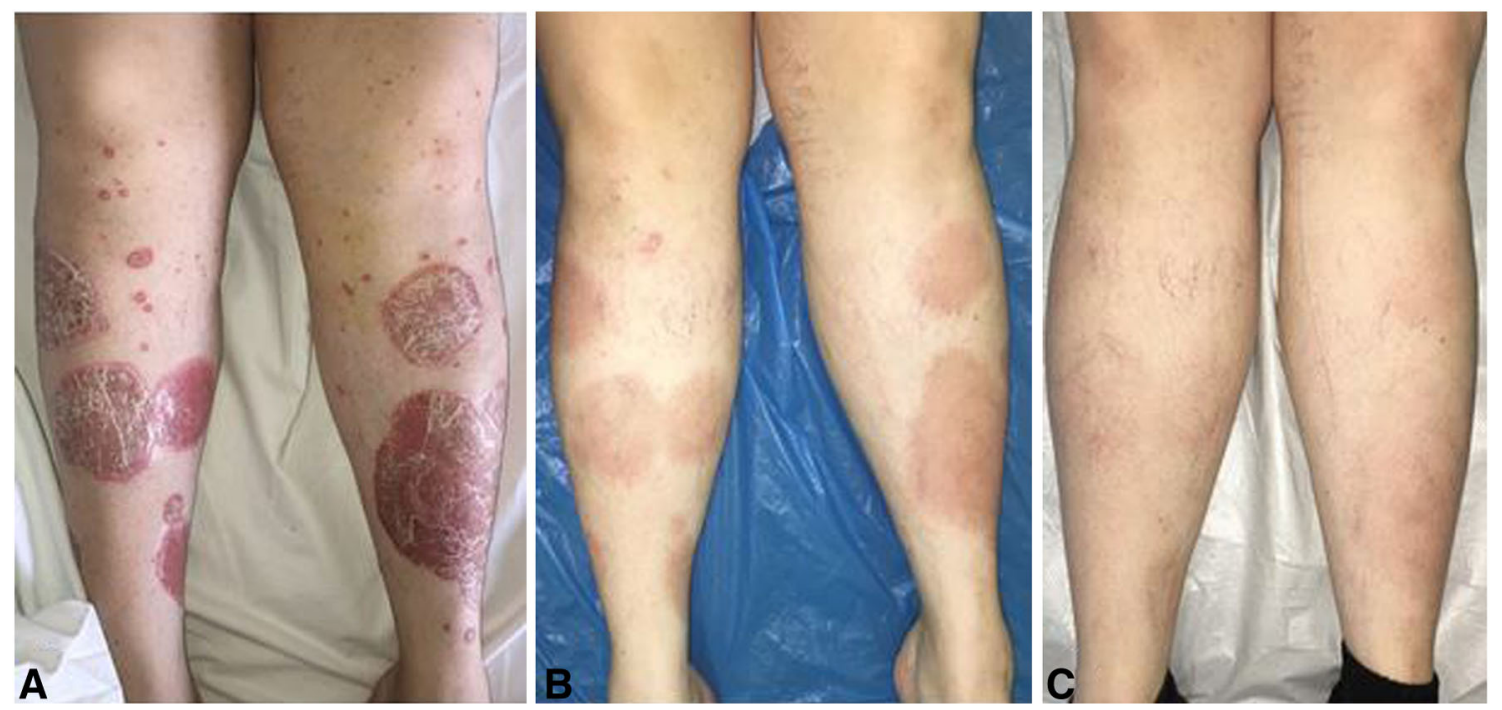

Fig. 1 a Skin involvement while on etanercept. b Marked improvement on week 4 of secukinumab administration. c Significant improvement on week 36 of secukinumab administration

As mentioned above, the number of patients with recalcitrant PsA has declined since the introduction of TNFi. Nevertheless, there are cases, like the one we present in the current report, that show a particular resistance to TNFi. Current guidelines propose the use of a second TNFi when the first TNFi fails to prove success regarding disease activity. Secukinumab is a new, promising biologic agent with rapid results and a good safety profile [11]. This is the first case the authors are aware of in Greece since the approval of secukinumab in January 2016 for the treatment of moderate-to-severe PsA showing significant improvement of synovitis and plaque psoriasis after failing in two TNFi and three sDMARDs. An interesting article from Kurosaki et al. describes a case of refractory psoriasis and pruritus, which became unresponsive to several biologics (ustekinumab, adalimumab, infliximab plus MTX). Treatment was switched to secukinumab, and after 32 weeks, PASI 100 was achieved [12].

Data from the clinical literature on switching bDMARD therapies in PsA are limited. In general, numerous bDMARDS have demonstrated efficacy in PsA, including the TNFi, the IL-12/23 inhibitor ustekinumab, and the IL-17A inhibitor secukinumab, but there are limited data on cases of recalcitrant PsA. The IL-17A inhibitor secukinumab is approved for the treatment of moderate-to-severe plaque psoriasis, ankylosing spondylitis, and PsA. Results of large-scale phase 3 studies indicate that secukinumab significantly improves the signs and symptoms of PsA in both TNFi-naive and TNFi-experienced patients.

Mease et al. [13], in a phase 3 study (FUTURE $1)$, reported that among patients who had a previous inadequate response to TNFi therapy or who had unacceptable side effects, an American College of Rheumatology 20\% improvement criteria (ACR20) response was reported in 23 of 59 patients (39\%) who received $150 \mathrm{mg}$ of secukinumab, 23 of 60 patients $(38.3 \%)$ who received $75 \mathrm{mg}$ of secukinumab, and ten of 59 patients (16.9\%) in the placebo group. In a post hoc analysis, ACR20 response rates were better in the secukinumab groups than in the placebo group at week 24, regardless of concomitant MTX use.

McInnes et al. [14], in a randomized, double-blind, placebo-controlled, phase 3 trial (FUTURE 2), showed that in prespecified exploratory analyses, ACR and PASI response rates were higher with secukinumab than with placebo in both TNFi-naive and TNFi-experienced patients with the magnitude of response generally being higher in the TNFi-naive population (Table 2). 
Table 2 Efficacy of secukinumab at week 24 in TNFinaive and TNFi-experienced patients

\begin{tabular}{lllll}
\hline & $\begin{array}{l}\text { ACR20 } \\
(\%)^{\mathbf{a}}\end{array}$ & $\begin{array}{l}\text { ACR70 } \\
(\%)\end{array}$ & $\begin{array}{l}\text { PASI75 }^{\mathbf{b}} \\
(\%)\end{array}$ & $\begin{array}{l}\text { PASI90 } \\
(\%)\end{array}$ \\
\hline $\begin{array}{l}\text { Secukinumab } \\
300 \mathrm{mg}\end{array}$ & & & & \\
TNFi-n & 58 & 22 & 63 & 53 \\
TNFi-e & 45 & 15 & 64 & 36 \\
Secukinumab & & & & \\
150 mg & & & & \\
TNFi-n & 63 & 27 & 56 & 39 \\
TNFi-e & 30 & 11 & 36 & 23 \\
Secukinumab & & & & 12 \\
75 mg & & & & \\
TNFi-n & 37 & 6 & 30 & 12 \\
TNFi-e & 15 & 6 & 24 & 12 \\
Placebo group & & & & 8 \\
TNFi-n & 16 & 2 & 19 & 10 \\
TNFi-e & 14 & 0 & 8 & 8 \\
\hline
\end{tabular}

a American College of Rheumatology 20\% improvement criteria

b Psoriasis Area and Severity Index

\section{CONCLUSIONS}

In conclusion, secukinumab seems to be a reasonable choice in cases of recalcitrant PsA patients to other biologic treatments due to the fact that IL-17A is an important factor involved in the pathogenesis of psoriatic lesions. In addition, downregulation of proinflammatory cytokines such as IL-1, IL-6, and TNF $\alpha$, possibly augment the therapeutic potency of secukinumab [15].

\section{ACKNOWLEDGEMENTS}

No funding or sponsorship was received for this study or publication of this article. The article processing charges were funded by the authors. All named authors meet the International
Committee of Medical Journal Editors (ICMJE) criteria for authorship for this manuscript, take responsibility for the integrity of the work as a whole, and have given final approval for the version to be published.

Author Contributions. All authors were involved in patient's care and approved the final version to be submitted for publication. Drafting and description of the case: EP. Patient care and clinical history: TM. Case revision: AAD, PVV.

Disclosures. Eleftherios Pelechas, Tereza Memi, Paraskevi V. Voulgari and Alexandros A. Drosos have nothing to disclose.

Compliance with Ethics Guidelines. Informed consent for the publication for this case report and any additional related information was taken from the patient involved in the study.

Open Access. This article is distributed under the terms of the Creative Commons Attribution-NonCommercial 4.0 International License (http://creativecommons.org/licenses/ by-nc/4.0/), which permits any noncommercial use, distribution, and reproduction in any medium, provided you give appropriate credit to the original author(s) and the source, provide a link to the Creative Commons license, and indicate if changes were made.

\section{REFERENCES}

1. Nikas SN, Voulgari PV, Takalou IP, Katsimbri P, Drosos AA. Healing of psoriatic skin lesions, and improvement of psoriatic arthritis resistant to immunosuppressive drugs, after infliximab treatment. Ann Rheum Dis. 2005;64(11):1665-7. doi:10. 1136/ard.2005.036178.

2. Wollina U, Conrad H. Treatment of recalcitrant psoriatic arthritis with anti-tumor necrosis factor-alpha antibody. J Eur Acad Dermatol Venereol. 2002;16(2):127-9. doi:10.1046/j.1468-3083.2002. 00391.x.

3. Nash P, Clegg DO. Psoriatic arthritis therapy: NSAIDs and traditional DMARDs. Ann Rheum Dis. 
2005;64(Suppl ii):74-ii77. doi:10.1136/ard.2004. 030783.

4. de Vlam K, Lories RJ. Remission in psoriatic arthritis. Curr Rheumatol Rep. 2008;10(4):297-302.

5. Atteno M, Peluso R, Costa L, Padula S, Iervolino S, Caso F, Sanduzzi A, Lubrano E, et al. Comparison of effectiveness and safety of infliximab, etanercept, and adalimumab in psoriatic arthritis patients who experienced an inadequate response to previous disease-modifying antirheumatic drugs. Clin Rheumatol. 2010;29(4):399-403. doi:10.1007/ s10067-009-1340-7.

6. Kristensen LE, Gulfe A, Saxne T, Geborek P. Efficacy and tolerability of anti-tumour necrosis factor therapy in psoriatic arthritis patients: results from the South Swedish Arthritis Treatment Group register. Ann Rheum Dis. 2008;67(3):364-9. doi:10. 1136/ard.2007.073544.

7. Saougou I, Markatseli TE, Papagoras C, Voulgari PV, Alamanos Y, Drosos AA. Sustained clinical response in psoriatic arthritis patients treated with anti-TNF agents: a 5-year open-label observational cohort study. Semin Arthritis Rheum. 2011;40(5):398-406. doi:10.1016/j.semarthrit.2010.07.004.

8. Mease PJ, Goffe BS, Metz J. Etanercept in the treatment of psoriatic arthritis and psoriasis: a randomised trial. Lancet. 2000;356(9227):385-90. doi:10.1016/S0140-6736(00)02530-7.

9. Kotsis K, Voulgari PV, Tsifetaki N, Machado MO, Carvalho AF, Creed F, et al. Anxiety and depressive symptoms and illness perceptions in psoriatic arthritis and associations with physical health-related quality of life. Arthritis Care Res. 2012;64(10):1593-601. doi:10.1002/acr.21725.

10. Lamb RC, Matcham F, Turner M, Rayner L, Simpson A, Hotopi $M$, et al. Screening for anxiety and depression in people with psoriasis: a cross-sectional study in a tertiary referral setting. Br J Dermatol. 2017;176(4):1028-34. doi:10.1111/bjd. 14833.

11. McInnes I, Sieper J, Braun J, Emery P, Van Der Heijde D, Isaacs J, Dahmen G. Anti-interleukin 17A monoclonal antibody secukinumab reduces signs and symptoms of psoriatic arthritis in a 24-week multicenter, double-blind, randomized, placebo-controlled trial. Arthritis Rheum. 2011;63(10):306.

12. Kurosaki Y, Takamori K, Suga Y. Refractory psoriasis vulgaris with itching successfully treated with the anti-interleukin-17A antibody secukinumab: a case of secondary failure of other biologic agents. Indian J Dermatol. 2017;62(4):441.

13. Mease PJ, McInnes IB, Kirkham B, Kavanaugh A, Rahman P, Heijde D, Landewe R, Nash P, Pricop L, Yuan J, Richards HB, Mpofu S. Secukinumab inhibition of interleukin-17A in patients with psoriatic arthritis (for the FUTURE 1 study group). N Eng J Med. 2015;373(14):1329-39. doi:10.1056/ NEJMoa1412679.

14. McInnes IB, Mease PJ, Kirkham B, Kavanaugh A, Ritchlin CT, Rahman P, Heijde D, Landewe R, Conaghan PG, Gottlieb AB, Richards H, Pricop L, Ligozio G, Patekar M, Mpofu S. Secukinumab, a human anti-interleukin-17A monoclonal antibody, in patients with psoriatic arthritis (FUTURE 2): a randomised, double-blind, placebo-controlled, phase 3 trial. Lancet. 2015;386(9999):1137-46. doi:10.1016/S0140-6736(15)61134-5.

15. Gutowska-Owsiak D, Schaupp AL, Salimi M, et al. IL-17 downregulates filaggrin and affects keratinocyte expression of genes associated with cellular adhesion. Exp Dermatol. 2012;21(2):104-10. 